\title{
Ética e atuação profissional: percepção de Agentes Comunitários de Saúde
}

\author{
Ethics and professional work: perception of \\ Community Health Agents
}

\author{
Artênio José Ísper Garbin¹, Cléa Adas Saliba Garbin, Suzely Adas Saliba Moimaz, \\ Diego Garcia Diniz ${ }^{2}$
}

Garbin AJl, Garbin CAS, Moimaz SAS, Diniz DG. Ética e atuação profissional: percepção de Agentes Comunitários de Saúde. Saúde, Ética \& Justiça. 2011;00(2):65-71.

RESUMO: A percepção do Agente Comunitário de Saúde (ACS) quanto à ética no seu trabalho foi avaliada neste estudo. Aplicou-se um questionário abordando conflitos éticos na prática assistencial em 61 ACS. $90 \%$ relataram terem recebido informações sobre o tema, sendo 'cursos profissionais' o meio mais citado (68,9\%). Em uma escala de 1 (mínimo) a 5 (máximo), 67\% alegaram possuir conhecimento a respeito da ética entre 4 ou 5 e $88,5 \%$ informaram que esse tópico tem uma importância de 5 no seu trabalho. Os conflitos éticos expostos obtiveram uma média de $75 \%$ das respostas em acordo com as fontes de referência, sendo que os itens envolvendo "privacidade de informação" apresentaram as maiores discordâncias. A ética foi considerada importante para a atuação profissional dos sujeitos, os quais obtiveram uma percepção adequada sobre a matéria, entretanto o tópico 'privacidade de informação' gerou controvérsias.

DESCRITORES: Serviços de saúde comunitária/recursos humanos; Serviços de saúde comunitária/ética; Ética profissional; Prática profissional/ética; Saúde da família.

\footnotetext{
${ }^{1}$ Professor Adjunto Doutor. Departamento de Odontologia Infantil e Social da Faculdade de Odontologia de Araçatuba - UNESP.

2 Pós-graduando (doutorado) em Odontologia Social e Preventiva. Faculdade de Odontologia de Araçatuba UNESP.

Endereço para Correspondência: Faculdade de Odontologia de Araçatuba - UNESP. Departamento de Odontologia Infantil e Social. Programa de Pós-Graduação em Odontologia Preventiva e Social. R. José Bonifácio, 1193. Araçatuba, SP. CEP: 16015-050. E-mail: diegogdiniz@ hotmail.com
} 


\section{INTRODUÇÃO}

A Estratégia de Saúde da Família (ESF) vem se consolidando no cenário atual como o principal modelo para a reorganização da atenção básica em saúde pública no Brasil. Nos últimos anos, temse observado melhorias nos indicadores de saúde nas áreas onde a estratégia está sendo implantada, fato que tem justificado sua ampliação'.

Uns dos principais atores sociais envolvidos diretamente no sucesso dessa iniciativa tem sido os Agentes Comunitários de Saúde (ACS). Esses profissionais desenvolvem uma das atividades mais peculiares dentro da ESF: a vinculação entre os profissionais da saúde e a população, ampliando a eficácia das ações de saúde favorecendo a participação da comunidade ${ }^{2}$.

Esse atributo característico faz com que o cotidiano das práticas dos ACS tenha uma dimensão muito importante na sua atuação dentro da assistência social. Dessa forma, é uma distinção do cuidado praticado pelo agente a proposta de aproximar a atenção básica e a saúde comunitária, costurando, assim, as dimensões técnica e política da assistência à saúde. E nessa dinâmica de seu oficio é que residem os conflitos, inclusive os de natureza ética ${ }^{3}$.

Sabe-se que a forma de atuação exigida pela ESF não se resume apenas a uma nova configuração da equipe técnica- assistencial, mas de um novo processo de trabalho marcado por uma prática ética, humana e vinculada ao exercício da cidadania. Sendo os ACS membros fundamentais para fazer frente ao desafio da concretização desse modelo, faz-se necessário lidar com as questões de ordem ética vivenciadas nos serviços de saúde, especialmente no caso da atenção básica, que tem sido preterida pelas reflexões bioéticas ${ }^{4}$.

\section{OBJETIVOS}

O presente estudo, atribuindo a importância do conhecimento e da utilização dos fundamentos teóricos e práticos de ética para um exercício profissional crítico e consciente, tem por objetivo avaliar a percepção dos Agentes Comunitários de Saúde (ACS) frente a conflitos éticos na sua prática assistencial, bem como a importância que eles atribuem a esse tema no cotidiano de seu trabalho.

\section{METODOLOGIA}

Esta pesquisa, de caráter descritivo- exploratória quantitativa, foi desenvolvida nas cinco Unidades de Saúde da Família do município de Sorocaba, SP, que abrangem uma população de aproximadamente 60.000 habitantes. Foram convidados para participar desse estudo todos os Agentes Comunitários de Saúde legalmente registrados e atuantes na Estratégia de Saúde da Família da cidade.

Como instrumento de coleta de dados e informações foi desenvolvido um questionário autoaplicável, devidamente validado através de parecer de especialistas, composto, na primeira parte, de 8 questões fechadas dicotômicas e de múltipla escolha com a finalidade de caracterizar - ACS, conforme dados sócio profissionais. $\mathrm{Na}$ segunda parte, 10 situações envolvendo conflitos éticos formulados a partir dos Códigos de Ética Médica $^{5}$, Odontológica ${ }^{6}$ e dos profissionais da Enfermagem $^{7}$ foram apresentadas aos sujeitos da pesquisa, sendo que os mesmos deveriam se posicionar quanto à veracidade ou não das afirmações. Na parte final, os ACS relataram qual o seu grau de conhecimento e a importância da ética na sua atuação profissional.

Para a análise dos dados foi utilizada a estatística descritiva com distribuição absoluta e relativa das respostas nas categorias investigadas.

O presente projeto foi aprovado pelo Comitê de Ética em Pesquisa da Universidade Estadual Paulista - UNESP - Campus de Araçatuba, SP - Faculdade de Odontologia, Processo Número 00647/2010, seguindo as normatizações presentes na Resolução 196/96 da Comissão Nacional de Ética.

\section{RESULTADOS}

A aplicação do questionário foi realizada em uma reunião de capacitação permanente dos ACS em que estavam presentes 61 dos 80 profissionais cadastrados do município, correspondendo a $76 \%$ dos indivíduos.

O perfil sócio- profissional dos sujeitos demonstrou serem eminentemente mulheres $(98 \%)$, casadas $(80 \%)$, possuindo entre 20 a 40 anos (82\%) e com filho(s) (82\%). A maioria cursou o ensino médio completo ( $80 \%$ ), tinha um tempo de atuação como ACS entre 1 e 5 anos (48\%), e tinha essa atividade profissional como sua única fonte de renda (69\%). Para $40 \%$ da amostra a opção pela profissão deveu-se ao fato de pertencer à área da saúde e $23 \%$ informaram que a escolheram devido à falta de outra oportunidade (Tabela 1). 
Tabela 1. Distribuição dos agentes comunitários de saúde segundo suas características sociodemográficas e profissionais, Sorocaba, SP, 2010

\begin{tabular}{lcc}
\hline \multicolumn{1}{c}{ Variáveis } & $\mathbf{n}$ & $\%$ \\
\hline Sexo & 1 & \\
Masculino & 60 & 98 \\
$\quad$ Feminino & \multicolumn{2}{c}{} \\
\hline Idade & 0 & 0 \\
Até 20 anos & 50 & 82 \\
De 20 a 40 anos & 11 & 18 \\
Acima de 40 anos & & \\
\hline Situação Conjugal & 8 & 13,1 \\
Solteira(o) & 49 & 80,3 \\
Casada(o)/com companheiro(a) & 4 & 6,6 \\
Separada(o)/divorciada(o) & 0 & 0 \\
Viúva(o) & & \\
\hline
\end{tabular}

\begin{tabular}{|c|c|c|}
\hline \multicolumn{3}{|l|}{ Filhos } \\
\hline $\operatorname{Sim}$ & 50 & 82 \\
\hline Não & 11 & 18 \\
\hline \multicolumn{3}{|l|}{ Escolaridade } \\
\hline Fundamental Completo & 2 & 3,3 \\
\hline Médio Incompleto & 3 & 4,9 \\
\hline Médio Completo & 49 & 80,3 \\
\hline Superior Incompleto & 3 & 4,9 \\
\hline Superior Completo & 4 & 6,6 \\
\hline \multicolumn{3}{|c|}{ Tempo de atuação como ACS } \\
\hline Até 1 ano & 13 & 21,3 \\
\hline De 1 a 5anos & 29 & 47,5 \\
\hline Mais de 5 anos & 19 & 31,2 \\
\hline \multicolumn{3}{|l|}{ Única fonte de renda } \\
\hline Sim & 42 & 68,8 \\
\hline Não & 19 & 31,2 \\
\hline \multicolumn{3}{|l|}{ Opção pela profissão } \\
\hline Vocação & 5 & 8,2 \\
\hline Salário & 5 & 8,2 \\
\hline Profissão da saúde & 24 & 39,3 \\
\hline Falta de oportunidade & 14 & 23 \\
\hline Satisfação pessoal & 9 & 14,7 \\
\hline Outro & 4 & 6,6 \\
\hline Total & 61 & 100 \\
\hline
\end{tabular}

Quanto às informações sobre o tema profissionais (68,9\%) e a formação escolar $(54,1 \%)$ ética, $90 \%$ relataram já terem recebido, sendo (Figura 1). Numa escala de 1 a 5 , sendo 10 que os meios mais mencionados foram os cursos mínimo e 5 o máximo, $67 \%$ alegaram possuir um 
conhecimento a respeito da ética em geral entre 4 ou 5 . Nessa mesma escala, $95 \%$ dos sujeitos investigados informaram que a ética possui uma importância entre 4 e 5 na atuação profissional dos ACS (Tabela2).

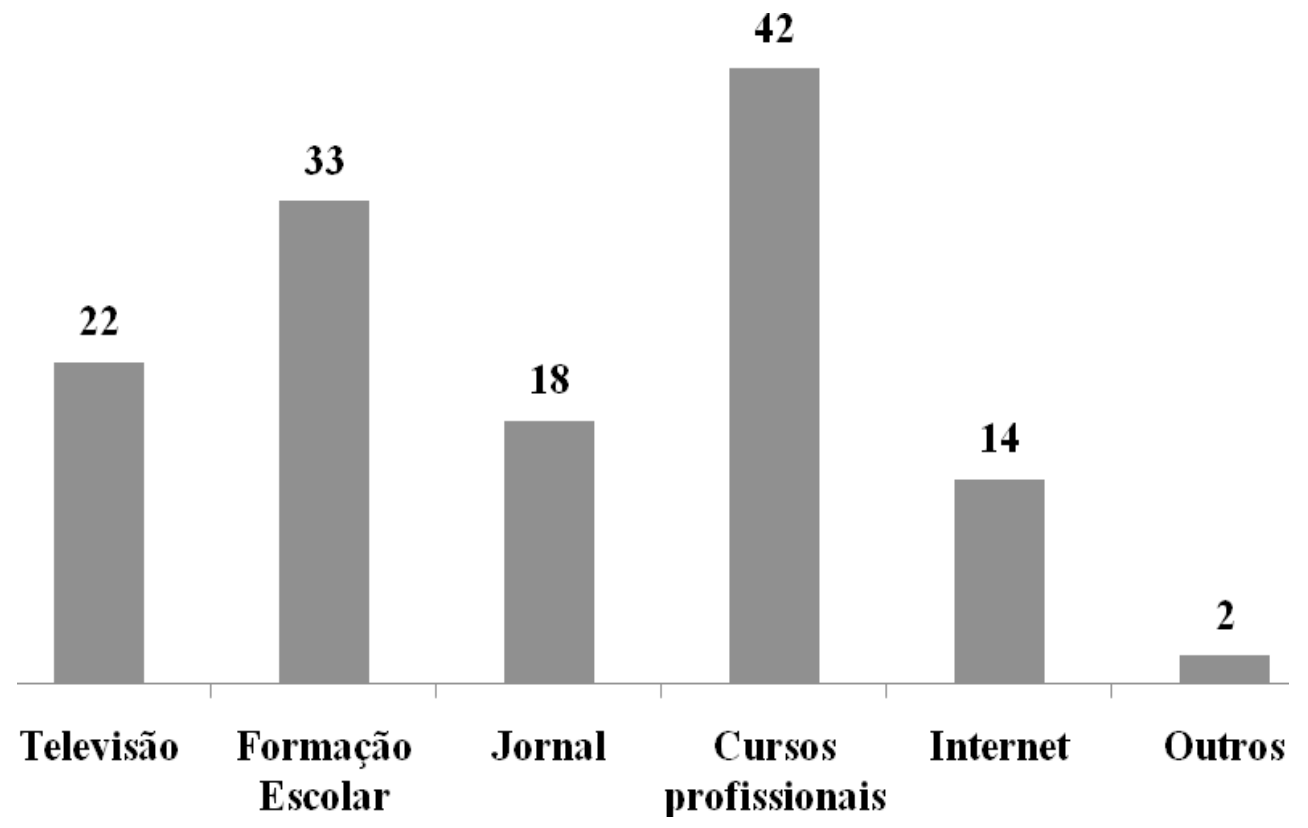

Figura 1. Meios de acesso a informações sobre ética citados pelos ACS, Sorocaba, SP, 2010

Tabela 2. A ética e o conhecimento de ACS, Sorocaba,SP, 2010

\begin{tabular}{lcc}
\hline \multicolumn{1}{c}{ Variáveis } & & \\
\hline $\begin{array}{l}\text { Acesso a informações sobre ética } \\
\text { Sim }\end{array}$ & $\mathbf{n}$ & $\%$ \\
Não & 55 & 90 \\
Conhecimento a respeito da ética & 6 & 10 \\
1 (mínimo) & 0 & \\
2 & 4 & 6 \\
3 & 16 & 26,2 \\
4 & 18 & 29,5 \\
5 (máximo) & 23 & 37,8 \\
Importância da ética na atuação do ACS & & \\
1 (mínimo) & 0 & 0 \\
2 & 1 & 1,6 \\
3 & 2 & 3,4 \\
4 & 4 & 6,5 \\
5 (máximo) & 54 & 88,5 \\
\hline Total & 61 & 100 \\
\hline
\end{tabular}

Em relação às questões que expuseram conflitos éticos, os resultados demonstraram uma média de acertos de $75 \%$ naquilo considerado eticamente adequado, de acordo com as fontes de referência utilizadas ${ }^{5-7}$. Os itens 6 e 10, que envolviam o assunto "privacidade de informação", apresentaram as maiores discordâncias (Tabela 3). 
TABELA 3. Posicionamento dos ACS em relação a situações hipotéticas envolvendo conflitos éticos vivenciados na prática profissional cotidiana, Sorocaba, SP, 2010

\begin{tabular}{|c|c|c|c|c|}
\hline \multirow[t]{2}{*}{ Questões } & \multicolumn{2}{|c|}{ Verdadeiro } & \multicolumn{2}{|c|}{ Falso } \\
\hline & $\mathbf{N}$ & $\%$ & $\mathbf{N}$ & $\%$ \\
\hline 1. A atenção à saúde deve ser realizada sobre princípios éticos. & 61 & 100 & 0 & 0 \\
\hline 2. Todo profissional de saúde conta com um código de ética. & 54 & 88,5 & 7 & 11,5 \\
\hline $\begin{array}{l}\text { 3. Apenas os profissionais de saúde que fazem atendimento clínico devem } \\
\text { agir eticamente. }\end{array}$ & 3 & 5 & 58 & 85 \\
\hline 4. O profissional de saúde pode ser punido se não agir de forma ética. & 61 & 100 & 0 & 0 \\
\hline $\begin{array}{l}\text { 5. Se o médico ou o dentista prescrever um tratamento ou outros } \\
\text { procedimentos sem examinar diretamente o paciente, ele esta agindo } \\
\text { eticamente. }\end{array}$ & 12 & 19,6 & 49 & 80,4 \\
\hline $\begin{array}{l}\text { 6. Se o enfermeiro revelar um fato importante ao médico sobre a saúde do } \\
\text { paciente sem a autorização prévia deste, ele cometeu uma falta ética. }\end{array}$ & 26 & 42,6 & 35 & 57,4 \\
\hline $\begin{array}{l}\text { 7. Se um profissional da saúde discriminar um paciente após este o ter } \\
\text { desrespeitado, ele não cometeu uma falta ética. }\end{array}$ & 20 & 16,4 & 41 & 83,6 \\
\hline $\begin{array}{l}\text { 8. O médico ou o dentista forneceu um atestado que não correspondia } \\
\text { à verdade dos fatos, então ele agiu em desacordo com os princípios } \\
\text { éticos. }\end{array}$ & 55 & 90 & 6 & 10 \\
\hline $\begin{array}{l}\text { 9. O profissional da saúde pode iniciar um tratamento não emergencial sem } \\
\text { autorização do paciente ou responsável, que ele não estará infringindo } \\
\text { o código ético. }\end{array}$ & 19 & 31 & 42 & 69 \\
\hline $\begin{array}{l}\text { 10. O profissional da saúde revelou um fato de que teve conhecimento em } \\
\text { virtude do exercício da profissão a outra pessoa que não tem relação } \\
\text { com a situação, então ele agiu de forma não ética. }\end{array}$ & 39 & 64 & 22 & 36 \\
\hline
\end{tabular}

\section{DISCUSSÃO}

O ACS é hoje uma das forças de trabalho mais expressivas no Brasil, constituindo por volta de 200 mil profissionais. Seu perfil tem-se mostrado semelhante em diferentes regiões ${ }^{8}$. Na sua maioria são mulheres, têm entre 20 e 40 anos, são casadas e com filho(s), e cursaram o ensino médio completo 5 . Esses dados são importantes, pois vários estudos consideram as influências de variáveis sociais na prática de atuação desses indivíduos bem como nas suas consequências ${ }^{9,10}$.

Mais de $50 \%$ da população brasileira está, atualmente, sob a responsabilidade, em termos de ações em saúde, do trabalho desses profissionais. Por todo esse grau de abrangência, a importância do ACS no contexto da atenção à saúde e pela sua característica peculiar de atuação, sendo um membro da comunidade-alvo e ao mesmo tempo integrante da equipe responsável pelas ações locais de saúde, a sua formação e também a maneira de atuar exigem uma diferenciação, refletindo diretamente no que se refere às questões éticas ${ }^{11}$.

Quanto a esse tema, no presente estudo,
$90 \%$ relataram já terem recebido alguma informação a sobre ética, entretanto as fontes citadas foram as mais diversas possíveis. Os sujeitos revelaram que a ética tem um grau de importância muito grande na sua atuação. Numa escala de 1 a 5 sendo 1 o mínimo e 5 o máximo chega a $95 \%$ proporção dos que informaram ter relevância entre 4 ou 5. Nessa mesma escala, $67 \%$ revelarem possuir um conhecimento a respeito da ética em geral entre 4 ou 5.

Entretanto, algumas colocações devem ser consideradas. Apesar do Programa de Agentes Comunitários de Saúde (PACS) ter sido implantado no Brasil em 1991, praticamente na mesma época do início do Sistema Único de Saúde (SUS), a profissão de ACS só foi criada e regulamentada em 2002, pela Lei $n^{\circ} 10.507$. Mesmo com essa regulamentação, algumas informações ficaram sem esclarecimentos precisos, como, por exemplo, a qual Conselho de Classe esse profissional estaria vinculado. Sabe-se que tais instâncias possuem Códigos de Ética que regulam os direitos e deveres dos profissionais a elas ligados, e esse fato faz com que os ACS fiquem destituídos de uma 
legislação nessa direção ${ }^{12,13}$. Dado curioso foi que $88,5 \%$ dos agentes investigados afirmaram que "Todo o profissional de saúde conta com um código de ética" não se atentando que justamente sua categoria profissional não o possui.

Outro quesito que vem despertando uma observação pertinente são as preocupações e dúvidas quanto às relações dos ACS com o direito dos usuários à privacidade das informações. Estudos têm apontado que parece ser consensual entre profissionais e gerentes das equipes de saúde que limites devam ser estabelecidos para - ACS com relação ao acesso a determinadas informações pessoais dos usuários ${ }^{14}$. Esse foi 0 evento que gerou a maior disparidade no presente estudo.

Quando indagados a respeito da exposição "Se o enfermeiro revelar um fato importante ao médico sobre a saúde do paciente sem a autorização prévia deste, ele cometeu uma falta ética", para $57,4 \%$ da amostra, ele não teria cometido falta ética e sobre a afirmação "O profissional da saúde revelou um fato de que teve conhecimento em virtude do exercício da profissão a outra pessoa que não tem relação com a situação, então ele agiu de forma não ética", 36\% confirmaram não existir desacordo ético.

Fica evidenciado que esse assunto gera controvérsias nos ACS pesquisados. Dentre os direitos dos usuários que podem ser garantidos em um projeto de humanização dos serviços de saúde está o direito à privacidade das informações. Este é um princípio derivado da autonomia, e engloba a intimidade, a vida privada, a honra das pessoas, significando que são os próprios indivíduos que têm direito de decidir que suas informações pessoais sejam mantidas sob seu exclusivo controle, como têm direito de comunicar a quem, quando, onde e em que condições as informações privadas devam ser reveladas ${ }^{15}$.

Assim, do direito do usuário à privacidade deriva o dever da manutenção do segredo por todos os elementos da equipe, lembrando que são sigilosas não somente as informações reveladas confidencialmente, mas são todas aquelas que a equipe de saúde descobre no exercício de sua atividade, mesmo havendo desconhecimento do usuário. Deste modo, o dever de manter o segredo das informações constitui-se em obrigação ética dos profissionais, dos técnicos, dos auxiliares, do corpo técnico e administrativo e dos $\mathrm{ACS}^{16}$.

Compreende-se, portanto, a necessidade de se dar mais atenção à formação profissional dos ACS. Esse processo deve proporcionar ao indivíduo capacitação para o trabalho de forma que ele não venha a ser um mero executor de tarefas, mas, sim, alguém competente, capaz de criar, sempre aliando o pensar ao agir e fazer, socialmente engajado e comprometido. Tal competência profissional implica, obviamente, no domínio de conhecimentos científicos e técnicos, mas também na capacidade de analisar, de refletir e de posicionar-se no sentido de transformar as condições de saúde e de vida dos assistidos e, nessa acepção, a ética constituise num elemento essencial ${ }^{17}$.

\section{CONCLUSÕES}

Os sujeitos da pesquisa indicaram possuir uma percepção adequada em relação aos conflitos éticos apresentados, entretanto o tema "privacidade de informação" gerou controvérsias entre os participantes. A ética foi considerada um elemento com alto grau de importância para a atuação profissional dos ACS.

Garbin AJI, Garbin CAS, Moimaz SAS, Diniz DG. Ethics and Professional work: perception of Community Health Agents. Saúde, Ética \& Justiça. 2011;00(2):65-71.

ABSTRACT: The perceptions of the Community Health Agent $(\mathrm{CHA})$ referred to ethics in their work have been evaluated in this study. A questionnaire with social and ethical issues was applied in $61 \mathrm{ACS}$. 90\% reported having received information about ethics, and "training courses" was the most cited source $(68.9 \%)$. On a scale from 1 (least) to 5 (maximum), $67 \%$ claimed to have knowledge about ethics among 4 or 5 and $88.5 \%$ reported that this topic has an importance of 5 in their work. Ethical conflicts exposed had an average of $75 \%$ of respondents in agreement with the reference sources, and the two items involving "information privacy" showed the greatest disagreement. Ethics was considered important by the professional performance of subjects who had a good perception about the issue; however the topic about privacy of information generated controversy.

KEYWORDS: Community health services/manpower; Community health services/ethics; Ethics, professional; Professional practice/ethics; Family Health. 


\section{REFERÊNCIAS}

1. Costa GD, Cotta RMM, Ferreira MLSM, Reis JR, Franceschini SCC. Saúde da família: desafios no processo de reorientação do modelo assistencial. Rev Bras Enferm. 2009;62(1):113-8.

2. Bornstein VJ, Stotz EN. Concepts involved in the training and work processes of community healthcare agents: a bibliographical review. Cienc Saúde Colet. 2008;13(1):259-68.

3. Silva JA. O agente comunitário de saúde e suas atribuições: os desafios para os processos de formação de recursos humanos em saúde. Interface. 2002;6(10):75-83.

4. Zoboli, ELCP, Fortes PAC. Bioética e atenção básica: um perfil dos problemas éticos vividos por enfermeiros e médicos do Programa Saúde da Família, São Paulo, Brasil. Cad Saúde Pública. 2004;20(6):1690-9.

5. Conselho Federal de Medicina. Código de Ética Médica. Brasília: CFM; 1988.

6. Conselho Federal de Odontologia. Resolução CFO42, Código de ética odontológica. Brasília: CFO; 2003.

7. Conselho Federal de Enfermagem. Código de ética dos profissionais de enfermagem. Rio de Janeiro: COREN; 1993.

8. Bornstein VJ, David HMSL, Araújo JWG. Agentes comunitários de saúde: a reconstrução do conceito de risco no nível local. Interface. 2010;14(32):93101.

9. Silva JA, Dalmaso ASW. Agente comunitário de saúde: o ser, o saber, o fazer. Rio de Janeiro: Fiocruz; 2002

10. Kluthcovsky ACGC, Takayanagui AMM, Santos CB, Kluthcovsky FA. Avaliação da qualidade de vida geral de agentes comunitários de saúde: a contribuição relativa das variáveis sociodemográficas e dos domínios da qualidade de vida. Rev Psiquiatr Rio Gd Sul. 2007;29(2):176-83.

11. Menicucci TMG. O Sistema Único de Saúde, 20 anos: balanço e perspectivas. Cad Saúde Pública. 2009;25:1620-5.

12. Nunes MO, Trad LB, Almeida BA, Homem CR, Melo $\mathrm{MCl}$. O agente comunitário de saúde: construção da identidade desse personagem híbrido e polifônico. Cad Saúde Pública. 2002;18:1639-46.

13. Ministério da Saúde. Lei no 10.507, de 10 de julho de 2002. Cria a profissão de agente comunitário de saúde e dá outras providências. Brasília: Ministério da Saúde; 2002.

14. Fortes PAC, Spinetti SR. O agente comunitário de saúde e a privacidade das informações dos usuários. Cad Saúde Pública. 2002;20(5):1328-333.

15. Sacardo DP, Fortes PAC. Desafios para a preservação da privacidade no contexto da saúde. Bioética. 2000;8:307-22.

16. Fortes PAC. Ética e saúde. São Paulo: Editora Pedagógica Universitária; 1998.

17. Garrafa V. A Dimensão da ética em saúde pública. São Paulo: Faculdade de Saúde Pública -US/ Kellogg Foundation; 1995. 